\title{
Valores Hematológicos y Lesiones Anatomopatológicas en Gallinas White Leghorn Afectadas por la Enfermedad Respiratoria Crónica
}

\author{
Hematological Values and Anatomopathological Lesions in White Leghorn \\ Hens Affected by Chronic Respiratory Disease
}

Manuel Colas C. ${ }^{1,5}$, Raiden Grandía G. ${ }^{2}$, Nelson Merino G. ${ }^{3}$, Yaima Burgher P. ${ }^{4}$, Michel Báez A. ${ }^{4}$, Ivette Espinosa C. ${ }^{4}$, José López R. ${ }^{1}$

\section{Resumen}

\begin{abstract}
La enfermedad respiratoria crónica (ERC) es considerada como una de las enfermedades infectocontagiosas de etiología múltiple que ocasiona grandes pérdidas económicas en la avicultura. Las manifestaciones clínicas y lesiones pueden ser muy severas cuando ocurren infecciones mixtas. Este complejo respiratorio ha estado presente en Cuba; sin embargo, no se conoce cómo varían los valores hematológicos en aves afectadas. El objetivo del presente estudio fue determinar los valores hematológicos y las lesiones anatomopatológicas en gallinas White Leghorn afectadas por la ERC. Se muestrearon 34 animales de 32 semanas de edad dentro de un foco activo ( 17 afectados y 17 clínicamente sanos) para la exploración clínica, necropsia, aislamiento e identificación de bacterias, y evaluación hematológica. Se compararon frecuencias de microorganismos y lesiones presentes, así como las medias de las variables hematológicas entre aves enfermas y sanas. Se evidenció la presencia de Ornithobacterium rhinotracheale, Mycoplasma gallisepticum y Escherichia coli solos o en infección mixta $(5.9-35.3 \%)$. Se observaron lesiones predominantes $(\mathrm{p}<0.05)$ como la traqueítis catarral $(76.5 \%)$, atrofia genital $(52.9 \%)$, aerosaculitis $(47.1 \%)$, rinoconjuntivitis fibrinosa y alteraciones hepáticas $(41.2 \%)$, entre otras. El análisis hematológico evidenció menores valores de hemoglobina $(8.9 \mathrm{~g} / \mathrm{dl})$, hematocrito $(29.7 \%)$ y leucocitos totales $\left(9.9 \times 10^{3} / \mathrm{mm}^{3}\right)$ con incremento de heterófilos (18.2\%) en animales enfermos en comparación con los sanos. Se concluye que en las aves afectadas por la ERC predominan las lesiones respiratorias y se afectan los valores hematológicos.
\end{abstract}

Palabras clave: enfermedad respiratoria crónica, hematología, lesiones anatomopatológicas, White Leghorn

\footnotetext{
${ }^{1}$ Instituto de Investigaciones Avícolas - IIA, Cuba

${ }^{2}$ Centro Nacional para la Producción de Animales de Laboratorio - CENPALAB, Cuba

${ }^{3}$ Centro para el Control Estatal de Medicamentos, Equipos y Dispositivos Médicos - CECMED, Cuba

${ }^{4}$ Centro Nacional de Sanidad Agropecuaria - CENSA, Cuba

${ }^{5}$ E-mail:manuelcc@unah.edu.cu
}

Recibido: 27 de noviembre de 2014

Aceptado para publicación: 25 de agosto de 2015 
The chronic respiratory disease (CRD) is considered as an infectocontagious disease of multiple etiology that causes great economic losses in poultry farming. The clinical signs and lesions in affected animals can be severe when mixed infections occur. In Cuba this respiratory complex is evident; however, it is not known how the hemathological values vary in affected fowls. The objective of this study was to determine the hemathological values and anatomopathological lesions in CRD affected White Leghorn hens. A total of 34 hens of 32 weeks of age were sampled in an affected flock (17 affected and 17 healthy) and was conducted the clinical evaluation, necropsy, isolation and identification of bacteria and hematological analysis. The frequencies of microorganisms and lesions present, as well as means of hematological variables between ill and healthy birds were compared. The presence of Ornithobacterium rhinotracheale, Mycoplasma gallisepticum and Escherichia coli were evidenced alone or in mixed infections (5.9$35.3 \%)$. Main lesion observed were catarrhal tracheitis (76.5\%), genital atrophy (52.9\%), airsacculitis (47.1\%), fibrinous rhinoconjunctivitis and hepatic alterations $(41.2 \%)(\mathrm{p}<0.05)$. The hematological analysis showed lower values of hemoglobin $(8.9 \mathrm{~g} / \mathrm{dl})$, hematocrit $(29.7 \%)$ and total leukocytes $\left(9.9 \times 10^{3} / \mathrm{mm}^{3}\right)$ with increase of heterophils $(18.2 \%)$ in ill animals in comparison with the healthy ones. It is concluded that in CRD affected fowls respiratory lesions are predominant and hematological values are affected.

Key words: chronic respiratory disease, hematology, anatomopathological lesions, White Leghorn

\section{INTRODUCCIÓN}

La enfermedad respiratoria crónica (ERC) es considerada como una enfermedad infectocontagiosa de etiología multifactorial (factores predisponentes) y multietiológica (agentes infecciosos virales, bacterianos y micóticos) y constituye una de las enfermedades más importantes dentro del grupo de las respiratorias, porque ocasiona grandes pérdidas económicas en la industria avícola moderna (Bradbury y Morrow, 2008; Sánchez y Lamazares, 2010).

Los hallazgos clínicos-anatomopatológicos observados en las aves son de variable severidad, debido a la participación de los factores predisponentes (Sánchez y Lamazares, 2010) y de la virulencia de los agentes microbianos que participen en el proceso, como los virus inmunosupresores en asociación con micoplasmas y Ornithobacterium rhinotracheale (Babaahmady et al., 2002; Merino, 2008).
Los principales signos clínicos descritos en la ERC son estertores traqueales y secreción nasal catarral bilateral (Bradbury y Morrow, 2008; Sánchez y Lamazares, 2010). Otros autores refieren signos severos (disnea, exudado nasal, tos, palidez de la cresta y barbillas, plumas erizadas y disminución del consumo de alimento con pérdida de peso) cuando ocurren infecciones mixtas por Avibacterium paragallinarum, $O$. rhinotracheale, Pasteurella sp, Bordetella avium, Escherichia coli, virus de la Bronquitis Infecciosa (BI), cepas de baja patogenicidad de la Enfermedad de Newcastle y de Influenza Aviar (El-Sukhon et al., 2002; Thachil et al., 2009).

Según Lobo et al. (2006), Muñoz et al. (2006) y Bradbury y Morrow (2008), las principales lesiones macroscópicas causadas por infecciones con Mycoplasma gallisepticum, $M$. synoviae y $M$. pullorum son la presencia de exudado mucoso y hemorragias en los senos nasales e infraorbitarios, laringe y tráquea. También se ha observado exudado 
Cuadro 1. Programa de vacunación en gallinas contra diferentes enfermedades (Cuba)

\begin{tabular}{lll}
\hline $\begin{array}{l}\text { Edad de vacunación } \\
\text { (días) }\end{array}$ & Vacuna & Vía de aplicación \\
\hline 1 & Marek & Subcutánea \\
1 & Bronquitis infecciosa & Aspersión \\
1 & Viruela aviar & Pliegue del ala \\
9 (asistida por serología) & Gumboro & Agua de bebida \\
14 & Newcastle & Aspersión \\
10 días después de la $1^{\text {ra }}$ dosis & Gumboro & Agua de bebida \\
35 & Bronquitis infecciosa & Aspersión \\
45 & Newcastle & Aspersión \\
$85-90$ & Bronquitis infecciosa & Aspersión \\
$105-110$ & Newcastle & Aspersión \\
\hline
\end{tabular}

fibrinoso que puede llegar hasta el acúmulo caseoso en las vías respiratorias superiores e inferiores, causado por infección simultánea de $E$. coli asociada a micoplasmas, $O$. rhinotracheale, B. avium y virus de la BI (Cavanagh, 2003; Spears et al., 2003; Van Empel, 2008; Sánchez y Lamazares, 2010). Se señala, en otros órganos, pericarditis fibrinopurulenta, hepatitis purulenta, peritonitis, salpingitis, atrofia genital y tendosinovitis (Lobo y Roche, 2000; Lobova et al., 2012).

Estas lesiones pueden llegar a causar anemia. Olson et al. (1968) refieren que la anemia puede estar asociada con enfermedades agudas y crónicas que suprimen la eritropoyesis u ocasionar la destrucción tóxica de los eritrocitos. Asimismo, Sturkie (1986) y Campbell (1995) indicaron que la edad, sexo, estación del año, producción de huevos, condiciones ambientales y agentes microbianos influyen sobre la composición de la sangre. En este sentido, los cambios hematológicos ante las diversas situaciones clínicas no han sido debidamente estudiados en Cuba, especialmente aquellas referidas a las aves domésticas con ERC. De allí que el presente estudio se trazó como objetivo determinar los valores hematológicos y las lesiones anatomopatológicas en gallinas White Leghorn afectadas por la ERC.

\section{MaTeRIALES Y MéTOdos}

\section{Tamaño, Selección y Toma de Muestra}

El estudio se realizó en una unidad de gallinas ponedoras $(n=65045)$ con foco activo de ERC (1\% de prevalencia), ubicada en la provincia Mayabeque de la región occidental de Cuba, donde se encuentra la mayor concentración de esta categoría de aves. La zona se encuentra a $50 \mathrm{msnm}$, con temperatura de $23{ }^{\circ} \mathrm{C}$ y humedad relativa de $75 \%$.

Se efectuó un muestreo tendencioso que comprendió 34 aves White Leghorn de 32 semanas de edad, siendo 17 con ERC (grupo afectado) y 17 sin manifestaciones clínicas (grupo sano). Los animales recibieron el alimento concentrado balanceado normado, mientras que el agua de bebida fue suministrada a libertad. 
Las aves fueron vacunadas según el programa de vacunación vigente en Cuba (Cuadro 1). Todas las gallinas ponedoras afectadas por la ERC manifestaron alguna forma clínica como disnea profusa, estertores, secreción nasal catarral bilateral, tumefacción facial en algunos casos con pérdida de la visión, además de palidez de la cresta y barbillas.

Las muestras de sangre para la evaluación hematológica se tomaron con jeringuilla de $5 \mathrm{ml}$ y aguja $21 \mathrm{G}$, por punción de la vena yugular. Se recolectaron en tubos estériles de $0.5 \mathrm{ml}$ que contenían EDTA como anticoagulante (Microtainer®) y con previa antisepsia de la zona de extracción con alcohol al 70\%. Las muestras fueron trasladadas al Laboratorio Clínico de la Dirección de Toxicología y Experimentación Animal del Centro Nacional para la Producción de Animales de Laboratorio (CENPALAB) y procesadas dentro de las cuatro horas de extraídas.

\section{Exploración Clínica y Necropsia}

Se realizó la exploración clínica y la necropsia según la metodología descrita por Sánchez y Lamazares (2010). El estudio macroscópico incluyó todos los órganos y el estado físico de las aves. Se registraron los resultados de todos los animales en los dos grupos en estudio.

\section{Aislamiento e Identificación de Bacte- rias}

Se hizo la detección de agentes bacterianos en todas las aves mediante procedimientos bacteriológicos.

\section{Bacterias}

Las muestras de exudados de senos paranasales, tráquea y pulmón se colectaron en microtubos de $1.5 \mathrm{ml}$ que contenían $500 \mu \mathrm{l}$ de PBS estéril. Los fragmentos de senos infraorbitarios y tráquea-pulmón se colocaron en tubos estériles. Las muestras de exudados y de órganos se sembraron en agar sangre, agar chocolate y agar MacConkey, todos procedentes del Centro Nacional de Biopreparados (BioCen). Las placas inoculadas se incubaron a $37{ }^{\circ} \mathrm{C}$ durante $48-72 \mathrm{~h}$ en presencia de $\mathrm{CO}_{2}$ (Genbox, Oxoid) y en condiciones de aerobiosis.

La identificación de las bacterias se realizó según las características culturales (morfología, tamaño, elevación y coloración de las colonias), empleando las pruebas de tinción de Gram, las pruebas bioquímicas como oxidasa (Oxoid), y los sistemas API 20NE y 20E (BioMérieux) (Hirsh et al., 2004).

\section{Micoplasmas}

Los exudados de senos paranasales, tráquea, pulmón y sacos aéreos se depositaron en dos tubos de cultivo que contenían $2.5 \mathrm{ml}$ de medio Micoplasma Base caldo con rojo fenol como indicador de $\mathrm{pH}$. Uno de ellos se incubó a $37^{\circ} \mathrm{C}$ en condiciones de aerobiosis y microaerofilia con una atmósfera de $0.5 \%$ de $\mathrm{CO}_{2}$ durante 21 días. El segundo tubo se utilizó para la extracción de ADN.

A partir de los cultivos que mostraron cambios de color, se sembraron $100 \mu \mathrm{l}$ en medios sólidos Micoplasma Base y se incubaron en las condiciones de aerobiosis y microaerofilia mencionadas anteriormente. Se observó la presencia de colonias típicas de micoplasmas con apariencia de 'huevo frito' con la ayuda de un microscopio óptico (Opton) de luz ordinaria a 400X.

Para el aislamiento de las colonias crecidas se cortó un bloque de $1 \mathrm{~cm}^{2}$ de las placas, se transfirieron a $2.5 \mathrm{ml}$ de medio Micoplasma Base, y se incubaron hasta la aparición de cambio de color, como se describió anteriormente, y nuevamente se sembró en medio sólido. Este procedimiento se repitió hasta la obtención de colonias aisladas. Finalmente, se tomó $1 \mathrm{ml}$ del cultivo para la identificación de $M$. gallisepticum mediante la prueba bioquímica de reducción de tetrazolium (Hirsh et al., 2004) y PCR especie específico (García et al., 2005). 


\section{Identificación Molecular}

La identificación de $O$. rhinotracheale y $M$. gallisepticum se realizó mediante la PCR con cebadores específicos para fragmentos de genes conservados en cada una de estas entidades, siguiendo las metodologías descritas por Van Empel (1998) y García et al. (2005). El ADN de las bacterias se purificó según la metodología descrita por Espinosa et al. (2011).

La extracción del ADN de Mycoplasma sp se realizó a partir de muestras de exudados de senos paranasales, tráquea, pulmón y sacos aéreos. Estas fueron colocadas en $1 \mathrm{ml}$ de PBS estéril, según la metodología de lisis física por calentamiento descrita por Fernández y Chávez (1999). Se empleó como control positivo el ADN de una cepa S6 de M. gallisepticum que forma parte de la colección del laboratorio MYCOLAB del Centro Nacional de Sanidad Agropecuaria (CENSA).

Los productos de la amplificación de la PCR se revelaron por electroforesis de ADN en gel de agarosa al 2\% (Sigma), con el uso de un marcador de peso molecular de $100 \mathrm{pb}$ (Bio-Rad). Las corridas se realizaron a $100 \mathrm{v}$ y $50 \mathrm{~mA}$ por 35 min en cámara de electroforesis 2012 Maxiphor (LKB Bromma) con buffer TBE $0.5 \mathrm{X}$, teñido con bromuro de etidio $(0.5 \mu \mathrm{g} / \mathrm{ml})$. Se empleó un transluminador de luz ultravioleta MacroVue (Pharmacia) para visualizar los productos amplificados.

\section{Evaluación Hematológica}

Se determinaron las variables hematológicas de hemoglobina, hematocrito, y cuenta total y diferencial de leucocitos. Adicionalmente se realizó la evaluación de la morfología celular. Para el conteo leucocitario (GB) se utilizó como diluyente la Solución Natt y Herrick referida por Campbell (1995). Se hizo el recuento total de leucocitos presentes en $9 \mathrm{~mm}^{3}$ del hemocitómetro o cáma- ra de Neubauer y el empleo de la fórmula siguiente: Total GB contados $+10 \%$ de los GB $\times 200=$ GB por microlitro (Campbell, 1995).

\section{Análisis Estadístico}

Primeramente se verificaron si los datos (variables hematológicas) seguían una distribución normal (método de KolmogorovSmirnov) y si cumplían con la homogeneidad de varianza (prueba de Levene). Al no seguir estos una distribución normal, se realizó la prueba no paramétrica Kruskal-Wallis para la comparación de medias (enfermos vs. sanos), y la prueba $\mathrm{T}$ de Student para las medias de aves positivas vs. negativas a $O$. rhinotracheale, M. gallisepticum y E. coli, apoyado por el paquete estadístico InfoStat v. 2.0 .

Se realizaron comparaciones de proporciones individuales entre los microorganismos aislados y entre las lesiones macroscópicas observadas (enfermos). Se utilizó la Dócima de Duncan para evidenciar las diferencias entre las variables estudiadas con el empleo del programa COMPAPRO v. 2.1. Para todos los casos se consideró una $\mathrm{p}<0.05$ como significación estadística en el análisis de los resultados.

\section{Resultados y Discusión}

Los resultados de la PCR confirmaron la presencia de $O$. rhinotracheale en tres aves (Figura 1) y M. gallisepticum en 12 aves (Figura 2).

En el Cuadro 2 se evidencia la presencia de $O$. rhinotracheale en infecciones simultáneas con $M$. gallisepticum y E. coli. Sin embargo, se encontraron aislados de $M$. gallisepticum sin asociación con otras bacterias, como también se demostró para el caso de E. coli. 
Cuadro 2. Frecuencia de microorganismos aislados en gallinas afectadas por la enfermedad respiratoria crónica (ERC)

\begin{tabular}{lc}
\hline Agentes microbianos & $\begin{array}{c}\text { Proporción } \\
(\%)\end{array}$ \\
\hline O. rhinotracheale + E. coli & 5.9 \\
O. rhinotracheale + M. & 11.8 \\
gallisepticum + E. coli & 23.5 \\
E. coli & 29.4 \\
M. gallisepticum + E. coli & 35.3 \\
M. gallisepticum & \\
\hline
\end{tabular}

NS: No significativo (EE $=0.10)$

En los casos donde se presentó el aislamiento de $O$. rhinotracheale en presencia de $M$. gallisepticum y $E$. coli se observaron lesiones macroscópicas en el sistema respiratorio debido a la inducción de estos agentes microbianos. La presentación de estas lesiones depende de la virulencia particular de cada uno de ellos, unido a las deficientes condiciones de bioseguridad de las instalaciones y del manejo de las aves que propician el estrés en las mismas (Reinhardt et al., 2005; Rahimi y Bahami, 2007; Sánchez y Lamazares, 2010).

Entre las lesiones macroscópicas que se apreciaron en las vías respiratorias superiores de las aves afectadas por la ERC, se destaca de manera significativa la traqueítis catarral, en comparación con la rinitis serosa, catarral y mucofibrinosa; sin embargo, no difiere de la rinoconjuntivitis fibrinosa (Cuadro $3)$.

La traqueítis catarral y rinitis catarral se presentan ante un estímulo causado por las bacterias en el sistema mucociliar de las aves afectadas por la ERC. El epitelio de las vías aéreas superiores (nasal y traqueal) constituye la línea de defensa principal, el cual posee dos mecanismos importantes, el celular (epitelio respiratorio) y el mecánico (sis- tema o escalador mucociliar), que impide la entrada de los agentes patógenos y partículas al hospedero (Zekaria, 2005).

La presencia de la rinitis mucofibrinosa y rinoconjuntivitis fibrinosa indicó el carácter crónico de la enfermedad debido a la infección mixta por $M$. gallisepticum, $O$. rhinotracheale y E. coli. Estos agentes microbianos están considerados como inductores de exudado de naturaleza fibrinosa mezclado con mucus. Barnes et al. (2003) y Sydenstricker et al. (2006) señalan que esta respuesta exudativa está presente en infecciones crónicas causadas por estos agentes microbianos que ingresan a través de los aerosoles.

La aerosaculitis se caracterizó por alteraciones que variaron desde la opacidad de los sacos aéreos hasta la exudación fibrinosa. La aerosaculitis fibrinosa observada en el presente estudio fue similar a la referida por Boado et al. (1988). En ese estudio epidemiológico, clínico y anatomopatológico de la ERC se encontraron tres grados de presentación de la aerosaculitis crónica fibrinosa y la clasificaron como leve (1.6\%), media (10.5\%) y grave $(57.9 \%)$.

La caquexia y la atrofia serosa de la grasa coronaria observadas en el presente estudio están descritas como lesiones resultantes de alteraciones en el metabolismo de los lípidos en los procesos consuntivos de la desnutrición, tras la inapetencia ocasionada por la infección mixta con varios agentes infecciosos que ingresan en el organismo ante situaciones de estrés, muy particular en esta categoría estudiada. Lo anterior coincide con lo planteado por Chamizo (2009), quien refiere a estas alteraciones fisiopatológicas asociadas con procesos crónicos.

La esplenomegalia se caracterizó por una hiperplasia de la pulpa blanca. Este hallazgo puede tener su origen por la infección con E. coli. Asimismo, la atrofia genital pudo deberse a la infección mixta y persistente por $M$. gallisepticum y E. coli identificadas en 


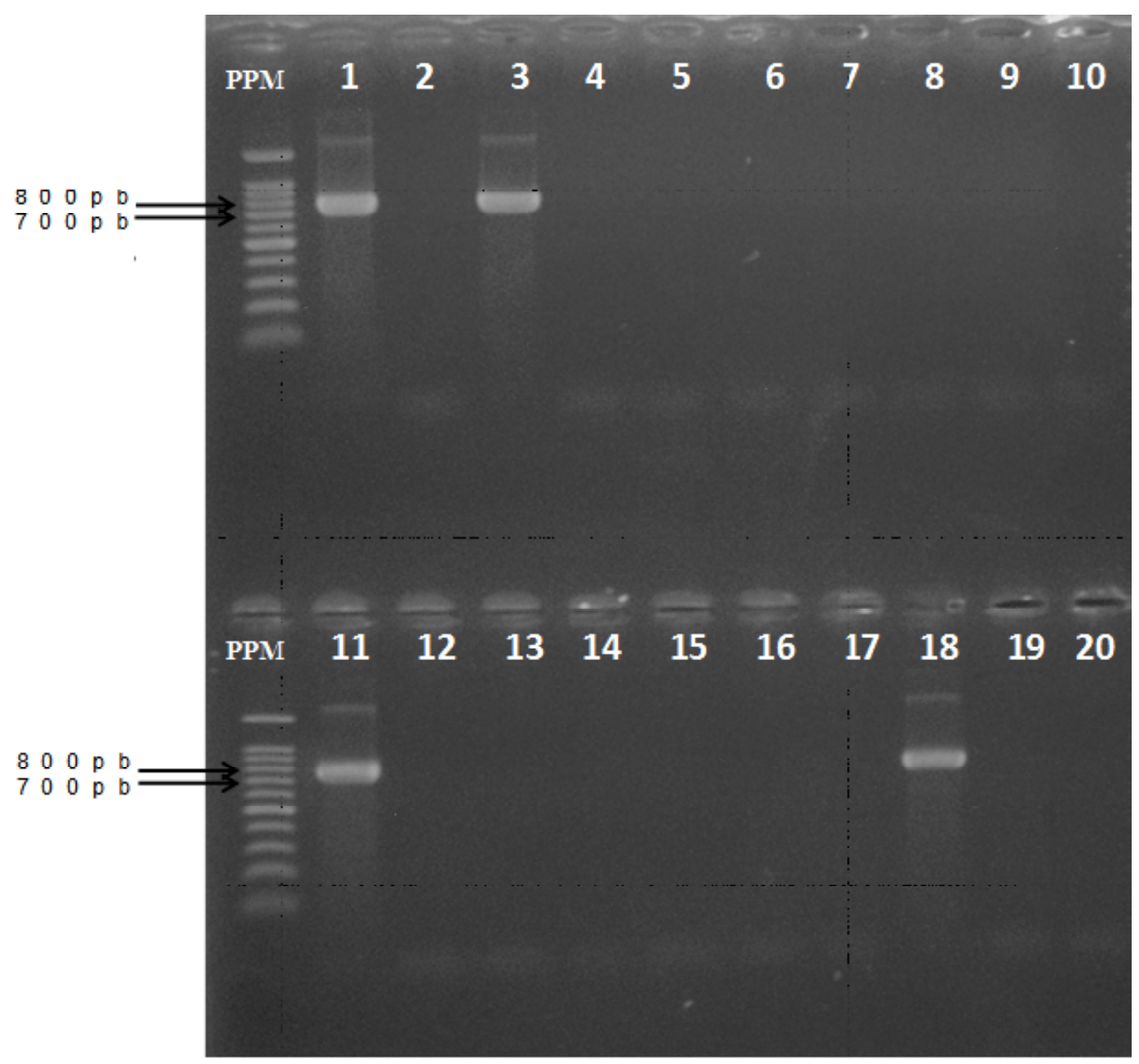

Figura 1. Electroforesis de ADN en gel de agarosa al 2\%. Detección de O. rhinotracheale en muestras clínicas. TBE $(0.5 \mathrm{X})$ teñido con bromuro de etidio $(0.5 \mu \mathrm{g} / \mathrm{ml})$. PPM: Patrón de peso molecular de $100 \mathrm{pb}$. Líneas 1, 3 y 11: Aislados de $O$. rhinotracheale. Línea 18: Control positivo, ADN de O. rhinotracheale. Línea 19: Control negativo, agua libre de nucleasas. Línea 20: Control negativo de extracción

estas aves. Por otro lado, los animales aparentemente sanos no evidenciaron lesiones en órganos y sistemas en la necropsia.

Aunque existe una gran variabilidad en los reportes de valores hematológicos de las aves en general, el hematocrito, la hemoglobina y los leucocitos son característicos de cada individuo y dependen en gran medida del método utilizado para su estimación (Sturkie, 1986).
Los valores de hemoglobina y leucocitos totales observados (Cuadro 4) se encontraron dentro del rango fisiológico descrito para esta especie (Bounus y Tedman, 2000), pero con considerables diferencias entre las aves afectadas por la ERC y las clínicamente sanas. El número total de leucocitos fue muy similar a los hallazgos obtenidos por Samour (2006) con valores de 1.9 a $9.5 \times 10^{3} / \mathrm{mm}^{3}$ y Tarun et al. (2011) con $10.6 \times 10^{3} / \mathrm{mm}^{3}$. Asimismo, los valores de hemoglobina fueron si- 


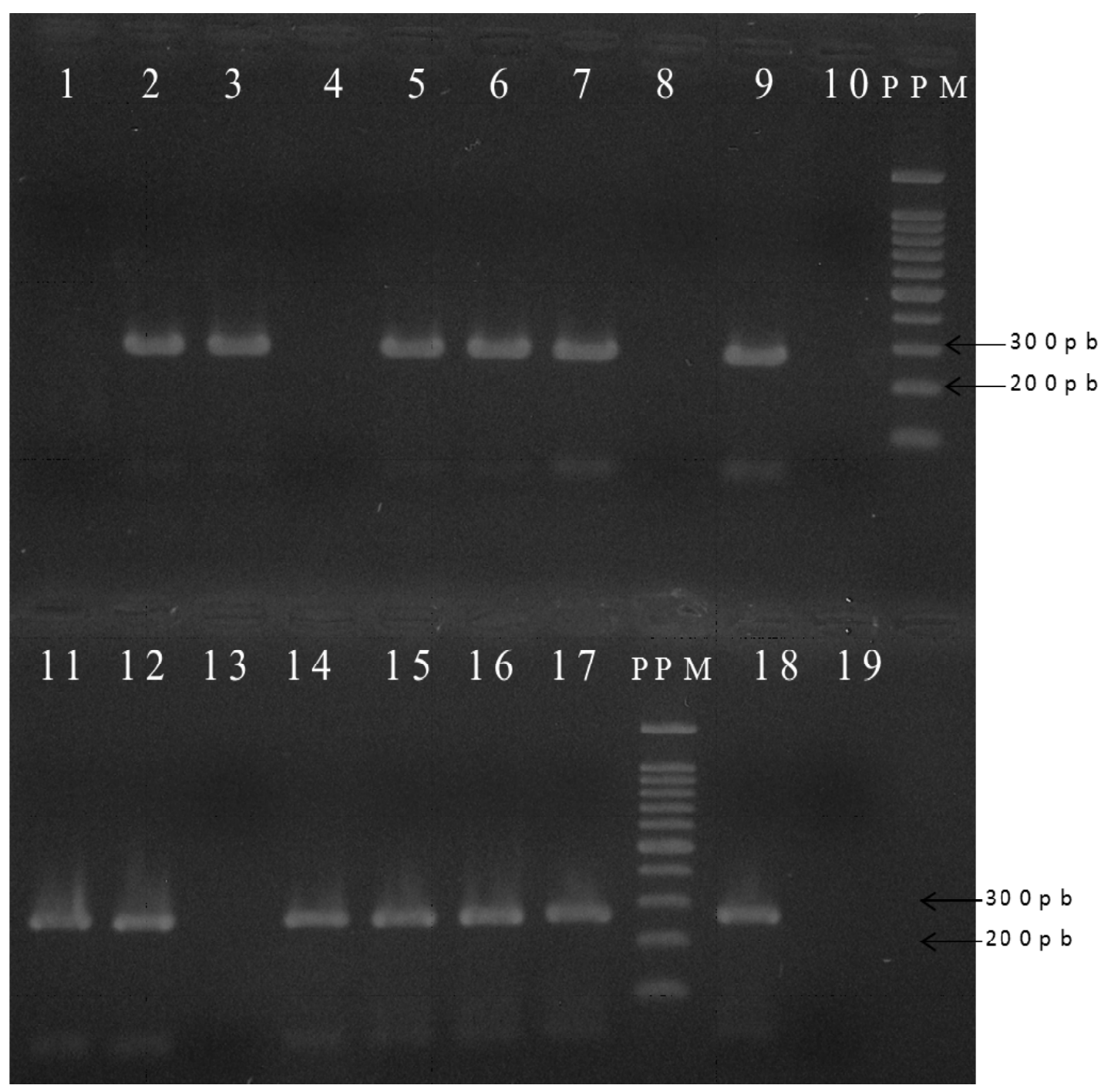

Figura 2. Electroforesis de ADN en gel de agarosa al 2\%. Detección de M. gallisepticum en muestras clínicas. TBE $(0.5 \mathrm{X})$ teñido con bromuro de etidio $(0.5 \mu \mathrm{g} / \mathrm{ml})$. PPM: Patrón de peso molecular de $100 \mathrm{pb}$. Líneas 2, 3, 5, 6, 7, 9, 11, 12, 14, 15, 16 y 17: Aislados de M. gallisepticum. Línea 18: Control positivo, ADN de M. gallisepticum. Línea 19: Control negativo, agua libre de nucleasas

milares a los reportados por Samour (2006) en Gallus domesticus con 10.2-15.1 g/dl, Martínez et al. (2012) en gallinas White Leghorn de 30 semanas de edad $(9.1 \mathrm{~g} / \mathrm{dl})$, y por Ajakaiye et al. (2010), quienes obtuvieron en Cuba valores de $8.9 \mathrm{~g} / \mathrm{dl}$ en esta raza ligera pero con 39 semanas de edad.
En el caso del hematocrito se evidenció una diferencia estadística $(\mathrm{p}<0.05)$ entre los dos grupos de aves (Cuadro 4), aunque ambos promedios se encuentran circunscritos en el rango fisiológico (22-35\%) notificado por Bounus y Tedman (2000). Asimismo, estos resultados fueron similares a los reportados 
Cuadro 3. Frecuencia de presentación de lesiones en gallinas afectadas por la enfermedad respiratoria crónica (ERC)

\begin{tabular}{lc}
\hline Lesiones macroscópicas & $\begin{array}{c}\text { Proporción } \\
(\%)\end{array}$ \\
\hline Bronconeumonía & $11.8^{\mathrm{a}}$ \\
Rinitis serosa & $17.6^{\mathrm{ab}}$ \\
Esplenomegalia & $17.6^{\mathrm{ab}}$ \\
Rinitis catarral & $23.5^{\mathrm{ab}}$ \\
Atrofia serosa de la grasa & $23.5^{\mathrm{ab}}$ \\
coronaria & $23.5^{\mathrm{ab}}$ \\
Caquexia & $35.3^{\mathrm{ab}}$ \\
Rinitis mucofibrinosa & $41.2^{\mathrm{abc}}$ \\
Rinoconjuntivitis fibrinosa & $41.2^{\mathrm{abc}}$ \\
Alteraciones hepáticas & $47.1^{\mathrm{abc}}$ \\
Aerosaculitis & $52.9^{\mathrm{bc}}$ \\
Atrofia genital & $76.5^{\mathrm{c}}$ \\
Traqueítis catarral & indican \\
\hline a,b,c Superíndices diferentes & lesiones \\
diferencias estadísticas entre & \\
(p<0.01; EE=0.12) &
\end{tabular}

por Samour (2006) con valores de 30 a $49 \%$, Ajakaiye et al. (2010) con 29.3\% y Martínez et al. (2012) con $29 \%$.

En relación con la evaluación diferencial de los leucocitos se encontraron diferencias estadísticas $(p<0.05)$ entre los grupos de aves (Cuadro 5), donde los valores de heterófilos fueron superiores en las aves afec- tadas por la ERC. Los valores de las aves clínicamente sanas fueron similares al valor de 7.6\% de heterófilos reportado por Samour (2006) y al de $10.7 \%$ en gallinas White Leghorn de 21 semanas de edad según Cheng et al. (2001).

Los valores predominantes de heterófilos observados en los animales afectados por la ERC, es un indicador de infección de origen bacteriano como se pudo demostrar tras el aislamiento e identificación de $O$. rhinotracheale, M. gallisepticum y E. coli (Figuras 1 y 2, Cuadro 2), pues estos constituyen la línea de defensa fundamental contra bacterias (Bounus y Tedman, 2000).

Los valores de linfocitos (Cuadro 5) fueron similares a los obtenidos por Hester et al. (1996) con $71.5 \%$ en gallinas White Leghorn de 33 semanas de edad, así como a los reportados por Cheng et al. (2001) con $83.4 \%$ en esta raza pero con 21 semanas de vida. Estos hallazgos también coinciden con Bounus y Tedman (2000), quienes indicaron en leucogramas normales el predominio de los linfocitos en sangre circulante, seguidos en orden por los heterófilos, monocitos, eosinófilos y basófilos. Es por ello, que en este conteo diferencial no se observaron basófilos ni eosinófilos en las 100 células analizadas por ave en ambos grupos.

Los valores de monocitos fueron similares en ambos grupos (Cuadro 5) y circunscritos dentro del rango descrito por Samour (2006) para Gallus domesticus (0-1\%), aunque se ha observado un valor de $2.6 \%$ en

Cuadro 4. Valores hematológicos en gallinas clínicamente sanas y afectadas por la enfermedad respiratoria crónica (ERC)

\begin{tabular}{lccc}
\hline Variables & $\begin{array}{c}\text { Aves con ERC } \\
(\text { media } \pm \mathrm{EE})\end{array}$ & $\begin{array}{c}\text { Aves sanas } \\
(\text { media } \pm \mathrm{EE})\end{array}$ & $\mathrm{p}$ \\
\hline Hemoglobina $(\mathrm{g} / \mathrm{dl})$ & $8.9 \pm 0.12$ & $10.4 \pm 0.2$ & 0.0003 \\
Hematocrito $(\%)$ & $29.7 \pm 0.4$ & $34.1 \pm 0.7$ & 0.0005 \\
Leucocitos totales $\left(\times 10^{3} / \mathrm{mm}^{3}\right)$ & $9.9 \pm 0.3$ & $11.0 \pm 0.4$ & 0.0041 \\
\hline
\end{tabular}


Cuadro 5. Leucograma diferencial en gallinas clínicamente sanas y afectadas por la enfermedad respiratoria crónica (ERC)

\begin{tabular}{lccc}
\hline Variables & $\begin{array}{c}\text { Aves con ERC } \\
(\text { media } \pm \text { EE) }\end{array}$ & $\begin{array}{c}\text { Aves sanas } \\
(\text { media } \pm \text { EE) }\end{array}$ & $\mathrm{p}$ \\
\hline Heterófilos $(\%)$ & $18.2 \pm 3.47$ & $8.3 \pm 1.46$ & 0.0097 \\
Linfocitos $(\%)$ & $81.2 \pm 3.57$ & $91.1 \pm 1.46$ & 0.0130 \\
Monocitos $(\%)$ & $0.6 \pm 0.28$ & $0.6 \pm 0.20$ & 0.8905 \\
\hline
\end{tabular}

Cuadro 6. Variables hematológicas y su relación con las entidades microbianas aisladas en gallinas afectadas por la enfermedad respiratoria crónica (ERC)

\begin{tabular}{|c|c|c|c|c|c|c|c|}
\hline \multirow{2}{*}{ Variables } & \multirow{2}{*}{$(+)$} & \multicolumn{2}{|c|}{ O. rhinotracheale } & \multicolumn{2}{|c|}{ M. gallisepticum } & \multicolumn{2}{|c|}{ E. coli } \\
\hline & & Media & $\mathrm{p}$ & Media & $\mathrm{p}$ & Media & $\mathrm{p}$ \\
\hline Hemoglobina $(\mathrm{g} / \mathrm{dl})$ & $\begin{array}{l}\text { Sí } \\
\text { No }\end{array}$ & $\begin{array}{l}7.87 \\
9.06\end{array}$ & 0.1348 & $\begin{array}{l}8.47 \\
9.78\end{array}$ & 0.0433 & $\begin{array}{l}8.48 \\
9.76\end{array}$ & 0.0487 \\
\hline Hematocrito (\%) & $\begin{array}{l}\text { Sí } \\
\text { No }\end{array}$ & $\begin{array}{l}26.77 \\
30.28\end{array}$ & 0.1962 & $\begin{array}{l}28.28 \\
32.96\end{array}$ & 0.0305 & $\begin{array}{l}28.43 \\
32.60\end{array}$ & 0.0484 \\
\hline $\begin{array}{l}\text { Leucocitos totales } \\
\left(\times 10^{3} / \mathrm{mm}^{3}\right)\end{array}$ & $\begin{array}{l}\text { Sí } \\
\text { No }\end{array}$ & $\begin{array}{l}9.10 \\
10.06\end{array}$ & 0.1394 & $\begin{array}{l}9.93 \\
9.80\end{array}$ & 0.8862 & $\begin{array}{c}9.79 \\
10.12\end{array}$ & 0.5570 \\
\hline Heterófilos (\%) & $\begin{array}{l}\text { Sí } \\
\text { No }\end{array}$ & $\begin{array}{l}31.00 \\
15.43\end{array}$ & 0.0359 & $\begin{array}{c}21.92 \\
9.20\end{array}$ & 0.0414 & $\begin{array}{l}21.25 \\
10.80\end{array}$ & 0.0218 \\
\hline Linfocitos (\%) & $\begin{array}{l}\text { Sí } \\
\text { No }\end{array}$ & $\begin{array}{l}68.33 \\
84.00\end{array}$ & 0.0402 & $\begin{array}{l}77.42 \\
90.40\end{array}$ & 0.0424 & $\begin{array}{l}78.08 \\
88.80\end{array}$ & 0.0220 \\
\hline Monocitos (\%) & $\begin{array}{l}\text { Sí } \\
\text { No }\end{array}$ & $\begin{array}{l}0.67 \\
0.57\end{array}$ & 0.8175 & $\begin{array}{l}0.67 \\
0.40\end{array}$ & 0.4356 & $\begin{array}{l}0.67 \\
0.40\end{array}$ & 0.4356 \\
\hline
\end{tabular}

otro reporte en gallinas White Leghorn con 21 semanas de edad (Cheng et al., 2001).

$\mathrm{Al}$ analizar las variables hematológicas y su relación estadística con las entidades microbianas aisladas en las gallinas afectadas por la ERC (Cuadro 6), se evidenció que los bajos valores medios de hemoglobina $\mathrm{y}$ hematocrito estuvieron asociados en orden de importancia con la presencia de $M$. gallisepticum y E. coli; mientras que los elevados niveles de heterófilos estuvieron relacionados en orden significativo con la presencia de $E$. coli, $O$. rhinotracheale y $M$. gallisepticum, como ya se señaló anteriormente.

En otro sentido, los valores de leucocitos totales y monocitos no se afectaron con la presencia de las bacterias identificadas. Asimismo, no se evidenciaron alteraciones hematológicas en la evaluación de la morfología celular. 
Se concluye que en las aves afectadas por la ERC predominan las lesiones respiratorias y se afectan los valores hematológicos.

\section{Literatura Citada}

1. Ajakaiye JJ, Pérez-Bello A, CuestaMazorra M, García-Díaz JR, Mollineda-Trujillo A. 2010. Effects of vitamin $\mathrm{c}$ and e dietary supplementation on erythrocyte parameters of layer chickens reared in high ambient temperature and humidity. Rev Bras Cienc Avic 12: 205-209. doi: 10.1590/ S1516-635X2010000300010

2. Babaahmady E, Joa R, Noda J, Rodríguez E, Alfonso P, Perera CL. 2002. Enfermedad infecciosa de la bolsa: efecto inmunosupresor en pollos de engorde. Rev Cub Cienc Avíc 26: 129135.

3. Barnes HJ, Vaillancourt JP, Gross WB. 2003. Colibacillosis. In: Saif YM, Barnes HJ, Glisson JR, Fadly AM, McDougald LR, Swayne DE (eds). Diseases of poultry. $11^{\text {th }}$ ed. USA: Iowa State University Press. p 631-656.

4. Boado E, Rejo T, Espinosa V, Fonseca C, Bacallao N. 1988. Factores epizootiológicos, clínicos y anatomopatológicos en la enfermedad respiratoria crónica complicada. Rev Cub Cienc Avíc 15: 83-94.

5. Bounus D, Tedman N. 2000. Normal avian hematology: chicken and turkey. In: Schalm's veterinary hematology. $5^{\text {th }}$ ed. USA: Lippincott Williams \& Wilkins. p 1145-1146.

6. Bradbury J, Morrow M. 2008. Avian mycoplasmas. In: Pattison M, McMullin PF, Bradbury JM, Alexander DJ (eds). Poultry diseases. $12^{\text {th }}$ ed. USA: Elsevier Limited. p 220-227.

7. Campbell T. 1995. Avian hematology. In: Campbell T (ed). Avian hematology and cytology. $2^{\text {nd }}$ ed. USA: Iowa State University Press. p 3-19.
8. Cavanagh D. 2003. Survey acute respiratory syndrome vaccine development: experience of vaccination. Avian Pathol 32: 567-582.

9. Chamizo PE. 2009. Patología orgánica y enfermedades de los animales domésticos. En: Chamizo PE (ed). $2^{a}$ ed. Cuba: Ed Félix Varela. p 1-6.

10. Cheng HW, Eicher SD, Chen $Y$, Singleton P, Muir WM. 2001. Effect of genetic selection for group productivity and longevity on immunological and hematological parameters of chickens. Poult Sci 80: 1079-1086.

11. El-Sukhon SN, Musa A, Al-Attar M.E. 2002. Studies on the bacterial etiology of airsacculitis of broilers in Northern and Middle Jordan with special reference to Escherichia coli, Ornithobacterium rhinotracheale, and Bordetella avium. Avian Dis 46: 605-612.

12. Espinosa I, Colas M, Vichi J, Báez M, Martínez S. 2011. Aislamiento e identificación de Ornithobacterium rhinotracheale en gallinas ponedoras de granjas de la provincia La Habana. Rev Salud Anim 33: 38-43.

13. Fernández C, Chávez Y. 1999. Aplicación de la reacción en cadena de la polimerasa para la detección de micoplasma en cultivos celulares. Rev Salud Anim 18: 31-34.

14. García M, Ikuta N, Levisohn S, Kleven SH. 2005. Evaluation and comparison of various PCR methods for detection of Mycoplasma gallisepticum infection in chickens. Avian Dis 49: 125-132.

15. Hester PY, Muir WM, Craig JV, Albright JL. 1996. Group selection for adaptation to multiple-hen cages: hematology and adrenal function. Poult Sci 75: 1295-1307.

16. Hirsh DC, MacLachlan NJ, Walker $\boldsymbol{R L} .2004$. Veterinary microbiology. $2^{\text {nd }}$ ed. USA: Wiley. $536 \mathrm{p}$.

17. Lobo E, Martínez S, Agüero JA, Chávez $Y$, Rosado I, Kleven $S$, Moscoso H, et al. 2006. Síndrome respiratorio crónico de las aves. Etiología, 
diagnóstico y control. Rev Cub Cienc Avíc 30: 27-40.

18. Lobo E, Roche C. 2000. Micoplasmas patógenos para las aves. Diagnóstico y control. Cuba: Ediciones CENSA. 20 p.

19. Lobova D, Kohoutova L, Molinkova D, Rosenbergova K, Kubicek O, Celer V. 2012. Prevalence of etiological agents of selected respiratory infections in chicken and turkey farms in the Czech Republic. Vet Med 57: 125-132.

20. Martínez Y, Escalona A, Martínez O, Olmo C, Rodríguez R, Maidelys I, Betancur C, et al. 2012. The use of Anacardium occidentale as nutraceutical in hypoprotein diets for laying hens. Cuban J Agr Sci 46: 395-401.

21. Merino AL. 2008. Histopatología de la bolsa de Fabricio en brotes de la enfermedad infecciosa de la bolsa. Rev Cub Cienc Avíc 32: 29-39.

22. Muñoz D, Bulnes C, Lobo E. 2006. Evaluación de la eficacia en condiciones controladas de una bacterina oleosa enriquecida contra el Síndrome Respiratorio Crónico en pollos de ceba. REDVET 7(9). [Internet]. Disponible en: http://www.veterinaria.org/revistas/ redvet/n090906/090604.pdf

23. Olson G, Biester HE, Schwarter LH. 1968. Enfermedades de las aves. Avicultura 30: 53-65.

24. Rahimi M, Bahami M. 2007. Isolation of Ornithobacterium rhinotracheale from the chickens of a broiler farm in Kermanshah province, west of Iran. Iranian J Vet Res 8: 355-359.

25. Reinhardt AK, Gautier-Bouchardon AV, Gicquel-Bruneau M, Kobisch M, Kempf I. 2005. Persistence of Mycoplasma gallisepticum in chickens after treatment with enrofloxacin without development of resistance. Vet Microbiol 106: 129-137. doi: 10.1016/j.vetmic. 2004.11.016

26. Samour J. 2006. Diagnostic value of hematology. In: Harrison GJ, Lightfoot TL (eds). Clinical Avian Medicine. Vol 2. USA: FL Spix. p 587-609.
27. Sánchez A, Lamazares MC. 2010. Principales enfermedades que afectan a las aves. Micoplasmosis aviar. En: Sánchez A, López A, García MC, Lamazares MC, Pérez M, Trujillo E, Sardá R (eds). Salud y producción de las aves. Cuba: Ed Félix Varela. p 212-532.

28. Spears PA, Temple LM, Miyamoto DM, Maskell DJ, Orndorff PE. 2003. Unexpected similarities between Bordetella avium and other pathogenic Bordetellae. Infect Immun 71: 25912597. doi: 10.1128/IAI.71.5.25912597.2003

29. Sturkie PD. 1986. Body fluids: blood. In: Sturkie PD (ed). Avian physiology. USA: Springer-Verlag. p 102-120.

30. Sydenstricker KV, Dhondt AA, Hawley MD, Jennelle CS, Kollias HW, Kollias GV. 2006. Characterization of experimental Mycoplasma gallisepticum infection in captive house finch flocks. Avian Dis 50: 39-44.

31. Tarun B, Seema A, Thaker AM. 2011. Hematological and biochemical changes due to short-term oral administration of imidacloprid. Toxicol Int 18(1): 2-4. doi: 10.4103/0971-6580.7584

32. Thachil AJ, Velayudhan VT, Shaw DP, Halvorson DA, Nagaraja KV. 2009. Pathogenesis of Ornithobacterium rhinotracheale in egg-laying hens with coexisting infectious bronchitis virus and Escherichia coli infections. J Appl Poult Res 18: 780-788. doi: 10.3382/japr.200900039

33. Van Empel P. 2008. Ornithobacterium rhinotracheale. In: Pattis on $\mathrm{M}$, McMullin PF, Bradbury JM, Alexander DJ (eds). Poultry diseases. $12^{\text {th }}$ ed. USA: Elsevier. p 164-171.

34. Van Empel P. 1998. Ornithobacterium rhinotracheale: current status and control. In: Proc I International Symposium on Turkey Diseases. Berlin, Germany. $\mathrm{p}$ 129-137.

35. Zekaria D. 2005. Síndrome respiratorio aviar. Interacciones y diagnóstico. En: Jornada de Profesionales de Avicultura de Carne. Valladolid, España. 